\title{
Valve-sparing repair of sinus of Valsalva aneurysm: Does early success predict long-term durability?
}

\author{
Benjamin C. Degner, MD, and Leonard N. Girardi, MD
}

\author{
From the Department of Cardiothoracic Surgery, Weill Cornell Medicine, New York, New York. \\ Disclosures: Authors have nothing to disclose with regard to commercial support. \\ Received for publication March 23, 2018; accepted for publication March 27, 2018; available ahead of print April \\ $21,2018$. \\ Address for reprints: Leonard N. Girardi, MD, 525 E. 68th St, M-404, New York, NY 10065 (E-mail: lngirard@ \\ med.cornell.edu). \\ J Thorac Cardiovasc Surg 2018;156:e85-6 \\ $0022-5223 / \$ 36.00$ \\ Copyright (C) 2018 by The American Association for Thoracic Surgery \\ https://doi.org/10.1016/j.jtcvs.2018.03.115
}

In this issue of the Journal, Pedroza and colleagues ${ }^{1}$ describe a 52-year-old female patient who presented with an acute coronary syndrome secondary to left main coronary compression from a large left sinus of Valsalva aneurysm (SVA). The patient underwent emergent valve-sparing aortic root replacement (VSRR) via a reimplantation technique. The left main followed an intramural course that required an unroofing procedure and bypass of the left anterior descending artery. The authors noted significant prolapse of the left coronary leaflet of the aortic valve and performed free-edge plication to resolve the aortic insufficiency (AI). The patient did well and was discharged on postoperative day 11. Mild AI was noted on a follow-up echocardiography obtained 1 month after surgery.

SVA is a rare cardiac condition reported in less than $0.15 \%$ of all patients undergoing open heart surgery. SVA is thought to occur as a result of incomplete fusion of the distal bulbar septum and truncal ridges and most commonly arises within the right coronary sinus. Associated congenital anomalies (ventricular and atrial septal defects) and varying degrees of AI are quite commonly present with SVA. Approximately $50 \%$ of patients will present in congestive heart failure and require emergent repair to alleviate the significant left-to-right shunting when aneurysms rupture and fistulize into adjacent cardiac chambers. The remainder require surgery when aneurysm growth is documented and progressive right ventricular outflow tract obstruction appears imminent. ${ }^{2}$ Coronary obstruction and ischemia is quite rare and, in this case, may have had as much to do with the intramural course of the left main coronary as the size of the SVA.

A number of surgical techniques have been espoused for repair of SVA. In 2 of the largest series in the literature, primary aneurysm plication and patch repair were by far the most commonly performed procedures. 2,3 However, primary repair has been associated with a greater risk of recurrent fistula formation ${ }^{4}$ and may be most appropriate when the aneurysm neck is $8 \mathrm{~mm}$ or less. ${ }^{3}$ Providing a

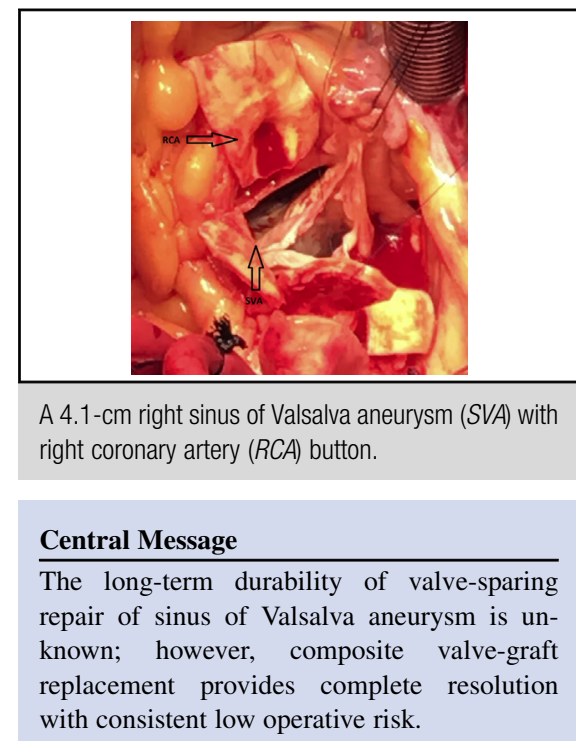

See Article page e81.

durable solution to AI in the presence of a SVA appears to be more complicated, as multiple pathologic mechanisms unite to create free-edge damage, cusp prolapse, and loss of

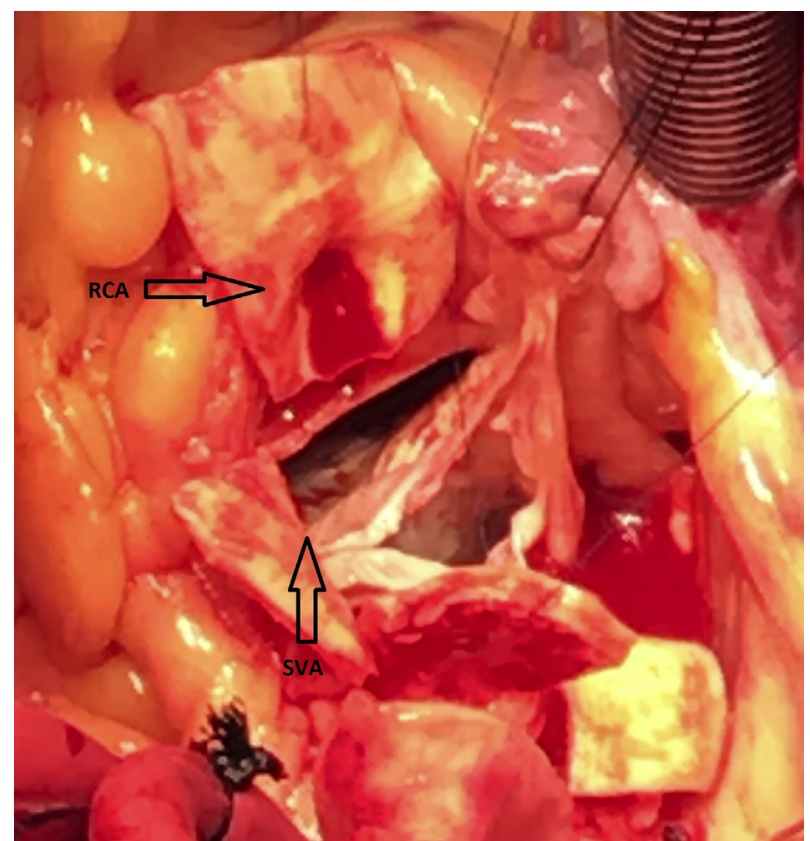

FIGURE 1. A 4.1-cm nonruptured right sinus of Valsalva aneurysm (SVA) with right coronary artery $(R C A)$ button prepared for composite valve-graft replacement. Note the paucity of annular tissue along right coronary cusp. 
annular support. Even in experienced hands, 9-year freedom from the need for reoperative aortic valve replacement was only $83 \%$ when SVA repair was accompanied by native aortic valve preservation. ${ }^{4}$ Composite valve-graft replacement provides complete resolution of root pathology with consistent low operative risk and excellent durability, ${ }^{5}$ albeit with the long-term risks of valve replacement. VSRR had previously been reported as a viable option for SVA repair. ${ }^{3,6}$ However, experience is limited, and long-term follow-up is nonexistent beyond 1 year. Given the paucity of quality aortic tissue above the annulus (Figure 1), the frequent need for correction of cusp prolapse and the potential for compromised patient hemodynamics, perhaps VSRR would be best used in the elective setting or by surgeons with extensive experience with complex aortic root reconstruction and aortic valve repair in a variety of clinical settings.

\section{References}

1. Pedroza AJ, Brewer ZE, Lee AM. Emergent valve-sparing aortic root replacement and coronary artery bypass grafting for giant left sinus of Valsalva aneurysm presenting as acute coronary syndrome. J Thorac Cardiovasc Surg. 2018;156:e81-4.

2. Takach TJ, Reul GJ, Duncan JM, Cooley DA, Livesay JJ, Ott DA, et al. Sinus of Valsalva aneurysm or fistula: management and outcome. Ann Thorac Surg. 1999; 68:1573-7.

3. Lin Y, Yin K, Wang Y, Guo C, Tian Z, Xie Q, et al. Sinus of Valsalva aneurysms with concomitant aortic insufficiency: how should the aortic valve be managed? Interact Cardiovasc Thorac Surg. 2018;26:210-5.

4. Azakie A, David TE, Peniston CM, Rao V, Williams WG. Ruptured sinus of Valsalva aneurysm: early recurrence and fate of the aortic valve. Ann Thorac Surg. 2000;70:1466-70.

5. Guadino M, Lau C, Munjal M, Avgerinos D, Girardi LN. Contemporary outcomes of surgery for aortic root aneurysms: a propensity-matched comparison of valvesparing and composite valve graft replacement. J Thorac Cardiovasc Surg. 2015; 150:1120-9.

6. Woo YJ, Frederick JR. Valve-sparing aortic root replacement and neochordal repair of complex aortic leaflet pathology for ruptured sinus of Valsalva aneurysm fistulizing to the right ventricle. Ann Thorac Surg. 2013;96: 1891-3. 